Bangladesh J. Bot. 42(1): 1-16, 2013 (June)

\title{
ROLE OF BACTERIA IN DIEBACK DISEASE OF DALBERGIA SISSOO ROXB.
}

\author{
Nayuf Valdez, Petr Karlovsky ${ }^{1}$, Lana Dobrindt ${ }^{2}$, M. Imdadul Hoque ${ }^{3}$, \\ Rakha Hari Sarker ${ }^{3}$, Hanny Tantau and Hans-Peter Mühlbach*
}

\author{
Molecular Phytopathology and Genetics, Biocentre Klein Flottbek, University of Hamburg, \\ Ohnhorststrasse 18, 22609 Hamburg, Germany
}

Key words: Dalbergia sissoo, Dieback disease, Plant pathogenic bacteria, Pseudomonas, Amplified Fragment Length Polymorphism (AFLP), Hypersensitive Response assay, Inoculation experiments

\begin{abstract}
The possible role of bacteria as pathogens in dieback affected Dalbergia sissoo Roxb. (sissoo) trees in Bangladesh has been investigated. Among the high diversity of bacterial genera detected by $16 \mathrm{~S}$ rDNA sequences, several plant pathogenic Pseudomonas strains were identified and classified by AFLP analysis. Three isolates produced significant symptoms on $D$. sissoo seedlings after mechanical inoculation in vivo, suggesting that Pseudomonas should be considered as a potential cause for the dieback disease.
\end{abstract}

\section{Introduction}

Dalbergia sissoo Roxb. is next to teak (Tectona grandis L.f.) the most planted tree in South Asia (Orwa et al. 2009). Timber of $D$. sissoo finds multipurpose uses in different fields and has a high economical impact on many South Asian countries. Since the early 50s, this tree species has been affected by a disease called 'wilt of shisham', which was first detected in India and blamed to infection by Fusarium solani Snyder \& Hansen (Bakshi 1954). While wilt of shisham was only observed in trees of about 15 - 25 years old (Bakshi 1954), a novel and probably different type of disease was observed in Bangladesh in the 1990s, which was also found in much younger trees in age classes from one up to 16 years (Basak et al. 2003). The disease has also been reported from Pakistan (Khan and Khan 2000) and Nepal (Sah et al. 2003). Various terms were used for the disease such as 'Mortality of sissoo' (Baksha and Basak 2000), 'Top dying disease' (Sah et al. 2003), 'Shisham decline' (Bajwa and Javaid 2007) and 'Dieback of sissoo' (Khan and Khan 2000), the latter one being used most frequently. The characteristic symptoms are yellowing and necrosis of the leaves, mostly starting from the top of the tree. Successive loss of leaves leads to the 'stag headed' symptom followed by occasional bark lesions with flow of dark red gum from the trunk.

Depending on the location, the progress of the disease varies (Dayaram et al. 2003), but in all cases the trees die within a few years. Drastic climatic changes such as the ones induced by the El Nino-Southern Oscillation (ENSO) could be a very important element in the spread of the disease (Collins et al. 2010). But rather than abiotic factors, various biotic agents have been discussed to be involved in the dieback disease of sissoo, such as the fungi Fusarium solani Snyder \& Hansen, Fusarium oxysporum Schlecht emend. Snyder \& Hansen, Ganoderma lucidum (Leyss.) Karst. and Phellinus gilvus Schwen. (Sharma et al. 2000, Baksha and Basak 2003). All of these organisms are known pathogens of $D$. sissoo, causing different types of symptoms. But since none of these organisms could be constantly isolated from dieback-affected trees, their role in the dieback of sissoo has not been convincingly demonstrated. Tantau et al. (2005) identified for the first time

*Author for correspondence: <muehlbach@botanik.uni-hamburg.de>. ${ }^{1}$ Molecular Plant Pathology and Mycotoxin Research, Georg-August University of Göttingen, Grisebachstrasse 6, 37077 Göttingen, Germany. ${ }^{2}$ Agricultural Entomology, Georg-August University of Göttingen, Grisebachstrasse 6, 37077 Göttingen, Germany. ${ }^{3}$ Department of Botany, University of Dhaka, Dhaka-1000, Bangladesh. 
bacterial isolates of the genera Bacillus and Pseudomonas in affected trees, which initiated a program to search for biotic agents other than fungi in more detail. These studies also suggested that viral infection was associated with sissoo dieback (Vogel et al. 2011), but in particular the involvement of bacteria of the genus Pseudomonas could be further substantiated (Tantau et al. 2011). The aim of the present study was to investigate the potential role of bacteria in the dieback disease of the $D$. sissoo, addressing more general aspects. Therefore samples collected from several locations in Bangladesh were screened for the presence of plant pathogenic bacteria. Isolates with putative pathogenic potential were further analyzed on a molecular and physiological basis.

\section{Materials and Methods}

Leaves and roots of Dalbergia sissoo Roxb. plants were collected at four locations in Bangladesh from a total of 12 trees, exhibiting various stages of dieback disease, as shown in Table 1, and used for isolation of bacteria. Additionally, D. sissoo seedlings grown from seeds (Sunshine-Seeds, Ahlen, Germany) under greenhouse conditions were used for infiltration tests with isolated bacteria. In order to isolate bacteria, $1 \mathrm{~g}$ of leaves or roots from sampled trees was homogenized in $100 \mathrm{ml}$ of a sterile $0.8 \% \mathrm{NaCl}$ solution. The homogenate was diluted $1: 100$ and $1: 10,000$ in $0.8 \% \mathrm{NaCl}$. A volume of 50 and $500 \mu \mathrm{l}$ of each dilution were plated on four different media: KM (King et al. 1954), LB (yeast reduced, Sambrook et al. 1989), YDC (Lakso et al. 1970 ) and NS (Schaad 1980), respectively. The plates were incubated at $28^{\circ} \mathrm{C}$ for two days. Selected bacterial colonies were streaked two more times on LB plates to obtain pure bacterial cultures.

The identification of the isolates was performed by single colony PCR using the universal primers Y1 and Y2 (Young et al. 1991). Each PCR-tube contained in a final volume of $25 \mu 1$ the following reagents: $1 \times$ concentrated PCR buffer, $0.2 \mathrm{U}$ Taq DNA polymerase, $0.2 \mathrm{mM}$ dNTP-mix and 10 pmoles of each primer. The routine PCR program consisted of 30 cycles of $30 \mathrm{~s}$ denaturation at $94^{\circ} \mathrm{C}, 1 \mathrm{~min}$ annealing at $61^{\circ} \mathrm{C}$ and $90 \mathrm{~s}$ of elongation at $72^{\circ} \mathrm{C}$. The PCR results were checked by electrophoresis in a $1.5 \%$ agarose gel. For sequencing 100 ng per $100 \mathrm{bp}$ of PCRproduct were mixed with $2 \mu$ Big Dye Enzyme, $6 \mu 12.5 \times$ buffer (PE Biosystem) and 15 pmol Y1 or Y2 primer $\left(25\right.$ cycles of $20 \mathrm{~s}$ denaturation at $96^{\circ} \mathrm{C}, 20 \mathrm{~s}$ annealing at $50^{\circ} \mathrm{C}$ and 4 min elongation at $60^{\circ} \mathrm{C}$ ). Sequences were analyzed using the program DNAstar and search in the NCBI and EMBL databases. The sequences obtained in this work were deposited in EMBL, accession numbers are listed in Table 1.

Gram staining was used for the microbiological characterization of Pseudomonas isolates. The morphological appearance of the bacteria was recorded (colour and surface structure) on yeast reduced LB-medium (Sambrook et al. 1989) and standard microbiological enzymatic activity tests for catalase and oxidase were performed.

For the extraction of secondary metabolites, single colonies of Pseudomonas isolates were inoculated into $10 \mathrm{ml} \mathrm{LB}$ medium and cultivated under constant shaking (200 rpm, New Brunswick Innova 44) for $24 \mathrm{hrs}$ at $28^{\circ} \mathrm{C}$. Bacteria were removed by centrifugation (10 min at $4500 \mathrm{rpm}$ ) and the supernatant was extracted two times with one volume of ethyl acetate. The organic phase was concentrated to dryness in a vacuum evaporator and the remaining material was resuspended in $10 \mathrm{ml} 0.8 \% \mathrm{NaCl}$ solution.

The hypersensitivity response (HR) test for Pseudomonas isolates was performed using $4 \mathrm{ml}$ aliquots of overnight cultures of bacteria. Cells were harvested by centrifugation, washed with $0.8 \% \mathrm{NaCl}$ and resuspended in $300 \mu \mathrm{l}$ of $0.8 \% \mathrm{NaCl}$. Solanum lycopersicum L., Nicotiana tabacum L. 'Xanthi' and Chenopodium quinoa Willd. were used as indicator plants. Usually, 100 
$\mu 1$ of cell suspension were infiltrated into the intercostal area of the leaves (two leaves per plant and per isolate) using a $1 \mathrm{ml}$ syringe without the needle. Necrosis or chlorosis at the infiltrated site obtained until the 4th day after inoculation was evaluated as a positive reaction. The extracted organic fractions were tested similarly but only on N. t. 'Xanthi'.

For amplified fragment length polymorphism (AFLP) genomic DNA was isolated from all Pseudomonas isolates by the CTAB method (Wilson 1997). The following reference strains were used: Pseudomonas oleovorans (DSMZ 1045), P. corrugata (DSMZ 7228), P. syringae (DSMZ 10604), P. tremae (DSMZ 16744), P. savastanoi (DSMZ 19341), P. fluorescens (DSMZ 50090), P. cichorii (DSMZ 50159), Clavibacter michiganensis (GSPB 3136). Extracted DNA was resuspended in TE-buffer $(10 \mathrm{mM}$ Tris/ $\mathrm{HCl}, 1 \mathrm{mM}$ EDTA, $\mathrm{pH}$ 8.0) to achieve a final concentration of $100 \mathrm{ng} / \mu \mathrm{l}$. AFLP was performed according to Vos et al. (1995) modified by using Tru1I (Reineke and Karlovsky 2000) and fluorescent labeling. DNA (200 ng) was successively restricted with EcoRI and Tru1I in $10 \mu \mathrm{l}$ reaction volume following the protocol given by Fermentas. After double digestion adapter molecules were ligated (EcoRI-Adapter 1: CTC GTA GAC TGC GTA CC, EcoRI-Adapter 2: AAT TGG TAC GCA GTC, Tru1I-Adapter 1: TAC TCA GGA CTC AT and TrulI-Adapter 2: GAC GAT GAG TCC TGA G) with T4-DNA-ligase (Fermentas) in $20 \mu \mathrm{l}$ reaction volume containing $10 \mu \mathrm{l}$ double-restricted DNA, 5 pmol EcoRIAdapter 1, 5 pmol EcoRI-Adapter 2, 50 pmol Tru1I-Adapter 1, 50 pmol Tru1I-Adapter 2, $1 \times$ concentrated T4-DNA-ligase-buffer and $1 \mu \mathrm{T}$ T4-DNA-Ligase. For preamplification $1 \mu \mathrm{l}$ of a 1 : 10 dilution in TE-buffer of the restriction-ligation-solution was used as template in $25 \mu \mathrm{l} \mathrm{PCR}$ reaction volume containing 10 pmol of EcoRI-00 primer (GAC TGC GTA CCA ATT C), 10 pmol Tru1I primer (GAC GAT GAG TCC TGA GTA $\underline{\mathrm{A}}$ ), $1 \times$ PCR-buffer (Bioline), $1.5 \mu 150 \mathrm{mM}$ $\mathrm{MgCl}_{2}$ (Bioline), $0.5 \mu 110 \mathrm{mM}$ dNTP-mix (Fermentas) and $0.3 \mu \mathrm{l} \mathrm{Taq-polymerase}$ (Bioline). The preamplification PCR-reaction was performed in a Biometra thermocycler Tpersonal 48 by using the following protocol: 25 cycles of $30 \mathrm{~s}$ denaturation at $94^{\circ} \mathrm{C}, 1 \mathrm{~min}$ annealing at $56^{\circ} \mathrm{C}$ and $1 \mathrm{~min}$ elongation at $72^{\circ} \mathrm{C}$. The preamplification products were then diluted $1: 10$ in TE-buffer and $1 \mu 1$ was used as a template for the amplification with primers containing selective nucleotides. Each PCR reaction contained additionally 5 pmol labelled EcoRI primer, 10 pmol MseI primer, $1 \times$ buffer (Bioline), $1.5 \mu 150 \mathrm{mM} \mathrm{MgCl} 2,0.5 \mu 110 \mathrm{mM}$ dNTP mix (Fermentas) and $1.5 \mathrm{u}$ Taqpolymerase (Bioline). For this selective PCR six different primer combinations were used with following primers: EcoRI-A_Dy750 (GAC TGC GTA CCA ATT CA-) and EcoRI-C_Dy681 (GAC TGC GTA CCA ATT Cㅁ) from Eurofins MWG Operon, MseI-A (GAC GAT GAG TCC TGA GTA AA), MseI-C (GAC GAT GAG TCC TGA GTA AC) and MseI-G (GAC GAT GAG TCC TGA GTA $\underline{\mathrm{AG}}$ ) from Invitrogen. The selective PCR was executed in a Biometra thermocycler Tpersonal 48 using the following protocol: 11 cycles of $30 \mathrm{~s}$ denaturation at $94^{\circ} \mathrm{C}$, $30 \mathrm{~s}$ annealing starting at $65^{\circ} \mathrm{C}$ and $1 \mathrm{~min}$ elongation at $72^{\circ} \mathrm{C}$. After each cycle the annealing temperature was decreased by $0.7^{\circ} \mathrm{C}$. The first 11 cycles were followed by 30 cycles of $30 \mathrm{~s}$ denaturation at $94^{\circ} \mathrm{C}, 1 \mathrm{~min}$ annealing at $56^{\circ} \mathrm{C}$ and $1 \mathrm{~min}$ elongation at $72^{\circ} \mathrm{C}$. Amplified fragments were analyzed by capillary electrophoresis using CQ8000 (Beckman Coulter, Brea, USA) under the following conditions: denaturation at $90^{\circ} \mathrm{C}$ for $120 \mathrm{~s}$ and separation for 80 min by $4.8 \mathrm{kV}$. The output of the Beckman Coulter Software is given as chromatograms, which were transformed into a presence/absence matrix. For fragment recognition the following parameter setting was used: a maximum Bin-Width (distance between the outer boundaries of each bin) of 1.25 nucleotides, a slope threshold of $10 \%$ and a relative peak height threshold of $10 \%$. The confidence level was set as $95 \%$. The applied model for calibration was the quartic curve model, which is recommended by Beckman to be selected when the Standard 600 of the company is being used. The matrix was then analyzed using the program NTSYS 2.0 (Rohlf 2000) for the clustering. The tree was calculated based on the similarity coefficient of Jaccard (1908) and clustered with the unweighted 
combination group method using arithmetic averages (UPGMA). For bootstrap the program Winboot was used. Jaccard similarity was calculated on Winboot as well.

D. sissoo plants were inoculated with four different bacterial strains (isolates 113, 1003, 1004 and 1008) selected according to the results of AFLP analysis. $25 \mathrm{ml}$ overnight cultures of each isolate were centrifuged at $3500 \mathrm{rpm}$ for $10 \mathrm{~min}$. The sediment was then suspended in $0.8 \% \mathrm{NaCl}$. The bacterial suspension (undiluted and diluted $1: 10$ ) was either injected into the axilla with a syringe $\left(20 \mathrm{G} \times 1 \frac{1}{2}\right)$ or administered through infiltration into the intercostal areas of the leaves. Eighteen $D$. sissoo plants (between six and twelve months old) were inoculated with each isolate by infiltrating 20 leaves per plant and isolate and 10 axilla per plant and isolate, respectively. For each method, two plants were mock inoculated with $0.8 \% \mathrm{NaCl}$ and water.

All statistical tests were performed using the software STATISTICA 8.0 (Statsoft, Tulsa, Oklahoma, USA). The symptom expression in $D$. sissoo leaves was assigned to levels (ranging from $1=$ no symptoms to $4=$ more than half of the plants with symptoms) and served as the dependent variable. Since the data did not meet the assumptions of normality it was analyzed with a generalized linear model (GLZ) using the logit link for ordinal data and model simplification with the factors 'treatment' (inoculation) and 'concentration' (pure or diluted 1:10) and their interaction. If a factor had a significant effect $(\mathrm{p}<0.05)$ and consisted of more than two factor levels it was further analyzed using the non-parametric Kruskal-Wallis-ANOVA and a corresponding post hoc analysis for non-parametric data (Siegel and Castellan 1988). Since homoscedasticity is an assumption of the Kruskal-Wallis-ANOVA the equivalency of variance of the data was tested with the Brown and Forsythe-Test (Brown and Forsythe 1974) that is used to compare the variances of non-normally distributed data. The data for the control treatment of the infiltrated and injected $D$. sissoo leaves was pooled for statistical analysis since it was not significantly different according to the non-parametric Mann-Whitney-U-Test.

\section{Results and Discussion}

In the present investigation of the bacterial flora in $D$. sissoo trees, the genus of 118 isolates from leaves and 18 isolates from roots of dieback-affected and symptom-free trees was identified by microbiological testing, PCR of $16 \mathrm{~S}$ rDNA and sequence analysis (Table 1).

Table 1. Bacteria isolated from Dalbergia sissoo trees showing different stages of dieback.

\begin{tabular}{lllll}
\hline $\begin{array}{l}\text { Geographical location of the } \\
\text { sampled tree/tree identifier }\end{array}$ & $\begin{array}{l}\text { Dieback } \\
\text { symptoms }\end{array}$ & Isolate & $\begin{array}{l}\text { EMBL } \\
\text { accession } \\
\text { number }\end{array}$ & $\begin{array}{l}\text { Putative genus } \\
\text { determined by partial } \\
\text { 16S rDNA sequence }\end{array}$ \\
\hline Tangail / P5 & No & 1D & FN822930 & $\begin{array}{l}\text { Pantoea } \\
\text { Tangail / P5 }\end{array}$ \\
Tangail / P5 & No & 1E & FN822931 & Curtobacterium \\
Tangail / P5 & No & $1 \mathrm{~K}$ & FN822932 & Pantoea \\
Dhaka / 11-1 & No & 173 & FN995135 & Klebsiella \\
Dhaka / 11-1 & No & 175 & FN995136 & Klebsiella \\
Dhaka / 11-1 & No & 176 & FN995137 & Pantoea \\
Dhaka / 11-1 & No & 177 & FN995138 & Pantoea \\
Dhaka / 11-1 & No & 178 & FN995139 & Pantoea \\
Dhaka / 11-1 & No & 179 & FN995140 & Enterobacter \\
\hline
\end{tabular}




\section{(Contd.)}

\begin{tabular}{|c|c|c|c|c|}
\hline $\begin{array}{l}\text { Geographical location of the } \\
\text { sampled tree/tree identifier }\end{array}$ & $\begin{array}{l}\text { Dieback } \\
\text { symptoms }\end{array}$ & Isolate & $\begin{array}{l}\text { EMBL } \\
\text { accession } \\
\text { number }\end{array}$ & $\begin{array}{l}\text { Putative genus } \\
\text { determined by partial } \\
\text { 16S rDNA sequence }\end{array}$ \\
\hline Dhaka / 11-1 & No & 180 & FN995141 & Pantoea \\
\hline Dhaka / 11-1 & No & 181 & FN995142 & Enterobacter \\
\hline Dhaka / 11-1 & No & 182 & FN995143 & Pantoea \\
\hline Dhaka / 11-1 & No & 183 & FN995144 & Aerococcus \\
\hline Dhaka / 12-1 & No & 161 & FN995125 & Uncultured bacterium \\
\hline Dhaka / 12-1 & No & 163 & FN995126 & Enterobacter \\
\hline Dhaka / 12-1 & No & 165 & FN995127 & Klebsiella \\
\hline Dhaka / 12-1 & No & 166 & FN995128 & Pantoea \\
\hline Dhaka / 12-1 & No & 167 & FN995129 & Pantoea \\
\hline Dhaka / 12-1 & No & 168 & FN995130 & Pantoea \\
\hline Dhaka / 12-1 & No & 169 & FN995131 & Acinetobacter \\
\hline Dhaka / 12-1 & No & 170 & FN995132 & Uncultured bacterium \\
\hline Dhaka / 12-1 & No & 171 & FN995133 & Uncultured bacterium \\
\hline Dhaka / 12-1 & No & 172 & FN995134 & Uncultured bacterium \\
\hline Jamuna Road / 8-1 & Mild & 194 & FN995151 & Enterobacter \\
\hline Jamuna Road / 8-1 & Mild & 195 & FN995152 & Staphyloccocus \\
\hline Jamuna Road / 8-1 & Mild & 196 & FN995153 & Uncultured bacterium \\
\hline Jamuna Road / 8-1 & Mild & 198 & FN995154 & Rhizobium \\
\hline Jamuna Road / 8-1 & Mild & 199 & FN995155 & Enterobacter \\
\hline Jamuna Road / 8-1 & Mild & 1002 & FN995156 & Uncultured bacterium \\
\hline Jamuna Road / 8-1 & Mild & 1003 & FN995157 & Pseudomonas \\
\hline Jamuna Road / 8-1 & Mild & 1004 & FN995158 & Pseudomonas \\
\hline Jamuna Road / 8-1 & Mild & 1006 & FN995159 & Pantoea \\
\hline Jamuna Road / 8-1 & Mild & 1007 & FN995160 & Pantoea \\
\hline Jamuna Road / 9-2 & Mild & 151 & FN995116 & Staphylococcus \\
\hline Jamuna Road / 9-2 & Mild & 152 & FN995117 & Pantoea \\
\hline Jamuna Road / 9-2 & Mild & 153 & FN995118 & Pseudomonas \\
\hline Jamuna Road / 9-2 & Mild & 154 & FN995119 & Pantoea \\
\hline Jamuna Road / 9-2 & Mild & 155 & FN995120 & Pseudomonas \\
\hline Jamuna Road / 9-2 & Mild & 156 & FN995121 & Enterococcus \\
\hline Jamuna Road / 9-2 & Mild & 157 & FN995122 & Uncultured bacterium \\
\hline Jamuna Road / 9-2 & Mild & 158 & FN995123 & Delftia \\
\hline Jamuna Road / 9-2 & Mild & 160 & FN995124 & Sphingomonas \\
\hline Tangail / P1 & Medium & 115 & FN822947 & Curtobacterium \\
\hline Tangail / P1 & Medium & 116 & FN822948 & Curtobacterium \\
\hline Tangail / P1 & Medium & 117 & FN822949 & Pseudomonas \\
\hline Tangail / P1 & Medium & 118 & FN822950 & Curtobacterium \\
\hline Tangail / P1 & Medium & 119 & FN822951 & Curtobacterium \\
\hline Tangail / P1 & Medium & 120 & FN822952 & Curtobacterium \\
\hline Tangail / P1 & Medium & 121 & FN822953 & Sphingomonas \\
\hline Tangail / P1 & Medium & 122 & FN822954 & Sphingomonas \\
\hline
\end{tabular}




\section{(Contd.)}

\begin{tabular}{|c|c|c|c|c|}
\hline $\begin{array}{l}\text { Geographical location of the } \\
\text { sampled tree/tree identifier }\end{array}$ & $\begin{array}{l}\text { Dieback } \\
\text { symptoms }^{1}\end{array}$ & Isolate & $\begin{array}{l}\text { EMBL } \\
\text { accession } \\
\text { number }\end{array}$ & $\begin{array}{l}\text { Putative genus } \\
\text { determined by partial } \\
\text { 16S rDNA sequence }\end{array}$ \\
\hline Tangail / P1 & Medium & 123 & FN822955 & Enterobacter \\
\hline Tangail / P1 & Medium & 124 & FN822956 & Pantoea \\
\hline Tangail / P1 & Medium & 125 & FN822957 & Acinetobacter \\
\hline Tangail / P6 & Medium & 126 & FN822958 & Pseudomonas \\
\hline Tangail / P6 & Medium & 101 & FN822934 & Pseudomonas \\
\hline Tangail / P6 & Medium & 102 & FN822935 & Pseudomonas \\
\hline Tangail / P6 & Medium & 103 & FN822936 & Pseudomonas \\
\hline Tangail / P6 & Medium & 104 & FN822937 & Pantoea \\
\hline Tangail / P6 & Medium & 105 & FN822938 & Pantoea \\
\hline Tangail / P6 & Medium & 106 & FN822939 & Burkholderia \\
\hline Tangail / P6 & Medium & 107 & FN822940 & Curtobacterium \\
\hline Tangail / P6 & Medium & 108 & FN822941 & Pantoea \\
\hline Tangail / P6 & Medium & 109 & FN822942 & Pantoea \\
\hline Tangail / P6 & Medium & 110 & FN822943 & Pseudomonas \\
\hline Tangail / P6 & Medium & 112 & FN822944 & Kocuria \\
\hline Tangail / P6 & Medium & 113 & FN822945 & Pseudomonas \\
\hline Tangail / P6 & Medium & 114 & FN822946 & Pseudomonas \\
\hline Tangail / P6 & Medium & 127 & FN822959 & Pseudomonas \\
\hline Tangail / P6 & Medium & 140 & FN822972 & Microbacterium \\
\hline Tangail / P6 & Medium & 141 & FN822973 & Xanthomonas \\
\hline Jamuna Road / 6-2 & Medium & 143 & FN822974 & Enterobacter \\
\hline Jamuna Road / 6-2 & Medium & 144 & FN822975 & Sphingomonas \\
\hline Jamuna Road / 6-2 & Medium & 145 & FN822976 & Pantoea \\
\hline Jamuna Road / 6-2 & Medium & 146 & FN822977 & Pseudomonas \\
\hline Jamuna Road / 6-2 & Medium & 147 & FN822978 & Pseudomonas \\
\hline Jamuna Road / 6-2 & Medium & 149 & FN822979 & Pseudomonas \\
\hline Jamuna Road / 6-2 & Medium & 150 & FN995115 & Pantoea \\
\hline Jamuna Road / 7-1 & Medium & 185 & FN995145 & Uncultured bacterium \\
\hline Jamuna Road / 7-1 & Medium & 186 & FN995146 & Rhizobium \\
\hline Jamuna Road / 7-1 & Medium & 187 & FN995147 & Pantoea \\
\hline Jamuna Road / 7-1 & Medium & 190 & FN995148 & Pantoea \\
\hline Jamuna Road / 7-1 & Medium & 191 & FN995149 & Sphingomonas \\
\hline Jamuna Road / 7-1 & Medium & 192 & FN995150 & Uncultured bacterium \\
\hline Bogra / 2-1 & Medium & 1032 & FN995182 & Pseudomonas \\
\hline Bogra / 2-1 & Medium & 1033 & FN995183 & Pseudomonas \\
\hline Bogra / 2-1 & Medium & 1034 & FN995184 & Klebsiella \\
\hline Bogra / 2-1 & Medium & 1020 & FN995173 & Klebsiella \\
\hline Bogra / 2-1 & Medium & 1021 & FN995174 & Uncultured bacterium \\
\hline Bogra / 2-1 & Medium & 1023 & FN995175 & Microbacterium \\
\hline Bogra / 2-1 & Medium & 1025 & FN995176 & Uncultured bacterium \\
\hline
\end{tabular}




\section{(Contd.)}

\begin{tabular}{|c|c|c|c|c|}
\hline $\begin{array}{l}\text { Geographical location of the } \\
\text { sampled tree/tree identifier }\end{array}$ & $\begin{array}{l}\text { Dieback } \\
\text { symptoms }^{1}\end{array}$ & Isolate & $\begin{array}{l}\text { EMBL } \\
\text { accession } \\
\text { number }\end{array}$ & $\begin{array}{l}\text { Putative genus } \\
\text { determined by partial } \\
\text { 16S rDNA sequence }\end{array}$ \\
\hline Bogra / 2-1 & Medium & 1026 & FN995177 & Uncultured bacterium \\
\hline Bogra / 2-1 & Medium & 1027 & FN995178 & Pseudomonas \\
\hline Bogra / 2-1 & Medium & 1032 & FN995182 & Pseudomonas \\
\hline Bogra / 2-1 & Medium & 1033 & FN995183 & Pseudomonas \\
\hline Bogra / 2-1 & Medium & 1034 & FN995184 & Klebsiella \\
\hline Tangail / P1 & Medium & 400 & FN995185 & Pantoea \\
\hline Tangail / P1 & Medium & 401 & FN995186 & Sphingomonas \\
\hline Tangail / P1 & Medium & 402 & FN995187 & Pseudomonas \\
\hline Tangail / P1 & Medium & 403 & FN995188 & Pseudomonas \\
\hline Tangail / P1 & Medium & 404 & FN995189 & Pantoea \\
\hline Tangail / P1 & Medium & 405 & FN995190 & Ralstonia \\
\hline Tangail / P1 & Medium & 406 & FN995191 & Enterobacter \\
\hline Tangail / P1 & Medium & 408 & FN995192 & Sphingomonas \\
\hline Tangail / P1 & Medium & 409 & FN995193 & Acinetobacter \\
\hline Tangail / P1 & Medium & 410 & FN995194 & Acinetobacter \\
\hline Tangail / P1 & Medium & 411 & FN995195 & Klebsiella \\
\hline Tangail / P1 & Medium & 412 & FN995196 & Rhizobium \\
\hline Tangail / P1 & Medium & 413 & FN995197 & Uncultured bacterium \\
\hline Tangail / P1 & Medium & 414 & FN995198 & Pseudomonas \\
\hline Tangail / P1 & Medium & 415 & FN995199 & Enterobacter \\
\hline Tangail / P1 & Medium & 416 & FN995200 & Pantoea \\
\hline Tangail / P1 & Medium & 418 & FN995201 & Pantoea \\
\hline Tangail / P1 & Medium & 419 & FN995202 & Klebsiella \\
\hline Tangail / P4 & Severe & 130 & FN822962 & Pseudomonas \\
\hline Tangail / P4 & Severe & 131 & FN822963 & Pseudomonas \\
\hline Tangail / P4 & Severe & 132 & FN822964 & Enterobacter \\
\hline Tangail / P4 & Severe & 133 & FN822965 & Agrobacterium \\
\hline Tangail / P4 & Severe & 134 & FN822966 & Curtobacterium \\
\hline Tangail / P4 & Severe & 135 & FN822967 & Rhizobium \\
\hline Tangail / P4 & Severe & 136 & FN822968 & Bacillus \\
\hline Tangail / P4 & Severe & 137 & FN822969 & Enterobacter \\
\hline Tangail / P4 & Severe & 138 & FN822970 & Microbacterium \\
\hline Tangail / P4 & Severe & 139 & FN822971 & Uncultured bacterium \\
\hline Bogra / 1-1 & Severe & 1008 & FN995161 & Pseudomonas \\
\hline Bogra / 1-1 & Severe & 1009 & FN995162 & Pantoea \\
\hline Bogra / 1-1 & Severe & 1010 & FN995163 & Pantoea \\
\hline Bogra / 1-1 & Severe & 1011 & FN995164 & Pseudomonas \\
\hline Bogra / 1-1 & Severe & 1012 & FN995165 & Pantoea \\
\hline Bogra / 1-1 & Severe & 1013 & FN995166 & Curtobacterium \\
\hline Bogra / 1-1 & Severe & 1014 & FN995167 & Klebsiella \\
\hline
\end{tabular}


(Contd.)

\begin{tabular}{lllll}
\hline $\begin{array}{l}\text { Geographical location of the } \\
\text { sampled tree/tree identifier }\end{array}$ & $\begin{array}{l}\text { Dieback } \\
\text { Symptoms }\end{array}$ & Isolate & $\begin{array}{l}\text { EMBL } \\
\text { accession } \\
\text { number }\end{array}$ & $\begin{array}{l}\text { Putative genus } \\
\text { determined by partial } \\
\text { 16S rDNA sequence }\end{array}$ \\
\hline Bogra / 1-1 & Severe & 1015 & FN995168 & Dyella \\
Bogra $/ 1-1$ & Severe & 1016 & FN995169 & Uncultured bacterium \\
Bogra $/ 1-1$ & Severe & 1028 & FN995179 & Uncultured bacterium \\
Bogra $/ 1-1$ & Severe & 1029 & FN995180 & Pantoea \\
Bogra / 1-1 & Severe & 1031 & FN995181 & Pantoea \\
\hline
\end{tabular}

${ }^{1}$ Dieback symptoms: No: Tree without typical dieback symptoms; mild: Chlorosis and necrosis on leaves as well as initial crown transparency; medium: Strong leaf necrosis, advanced crown transparency, gummosis and necrosis (black spots) at the bottom parts of the trunk; severe: Almost all foliage and most of twigs and branches of higher order lost (stagheadedness), black spots at the trunk up to at least $2 \mathrm{~m}$ height.

These 136 operational taxonomic units (OTUs) represented at least 19 different genera. Within this broad bacterial spectrum, the most prominent genera were Pseudomonas with 28 isolates and Pantoea with 14 isolates (Table 1). With one exception (isolate 1K) Pseudomonas isolates were only found in dieback-affected trees, predominantly at locations Tangail, Jamuna Road and Bogra, while Pantoea isolates were identified in all sampled trees in Bangladesh, irrespective of their disease status. Also, 11 isolates of the genus Enterobacter, known to comprise bacteria with plant pathogenic potential (Nishijima et al. 1987, Takahashi et al. 1997), and ten isolates of the Gram-positive and plant pathogenic genus Curtobacterium (Dunleavy 1989) were found in samples of dieback-affected as well as unaffected sissoo trees. A few $\gamma$-proteobacteria of the genus Acinetobacter and Klebsiella, not yet known as plant pathogenic agents, were additionally found in unaffected and dieback-affected trees. Six isolates of the genus Sphingomonas were identified in dieback-affected trees only, as was the case for the sporadically occurring isolates of other plant pathogenic Gram-negative genera, such as Agrobacterium (Escobar and Dandekar 2003), Burkholderia (Coenye and Vandamme 2003), Xanthomonas (Kay and Bonas 2009, White and Yang 2009), Ralstonia (Guidot et al. 2009) and Rhizobium. Rarely further Gram-positive bacteria were found such as Kocuria, Microbacterium, and Staphylococcus. All these isolates were associated with dieback-affected sissoo samples. With the obtained 16S rDNA sequences a phylogram was constructed (Fig. 1) that showed two clusters of Pseudomonas (marked blue) and of Pantoea (marked orange), suggesting the presence of more than one species in both cases.

The genus Pantoea comprises eight species that are generally related with plants either as pathogen or as epi-/endophyte (Brady et al. 2011, Delétoile et al. 2009). Present authors found the Pantoea isolates distributed in two clusters with very high bootstrap values of 100 and $98 \%$, respectively (Fig. 1), suggesting at least two different species of Pantoea. Seven other isolates grouping close to the Pantoea cluster could not be identified, but the bootstrap values showed that these must be either very closely related bacteria (i.e. genus Enterobacter, isolate 179) or a Pantoea species that has not been characterized so far $(1002,1021)$. One Pantoea-cluster (orange marked isolates with a bootstrap value of $100 \%$ ) is built up only by isolates from affected trees. In the other Pantoea-cluster various isolates were also found in two trees without dieback-symptoms (Table 1).

The cluster of Pseudomonas isolates is also distributed into two subclusters, a highly homogeneous one, where the majority of the isolates are found, while a minority of only six isolates was clustering in a more heterogeneous subcluster. This cluster organization probably reflects the presence of at least two species of this highly complex genus among the bacteria 


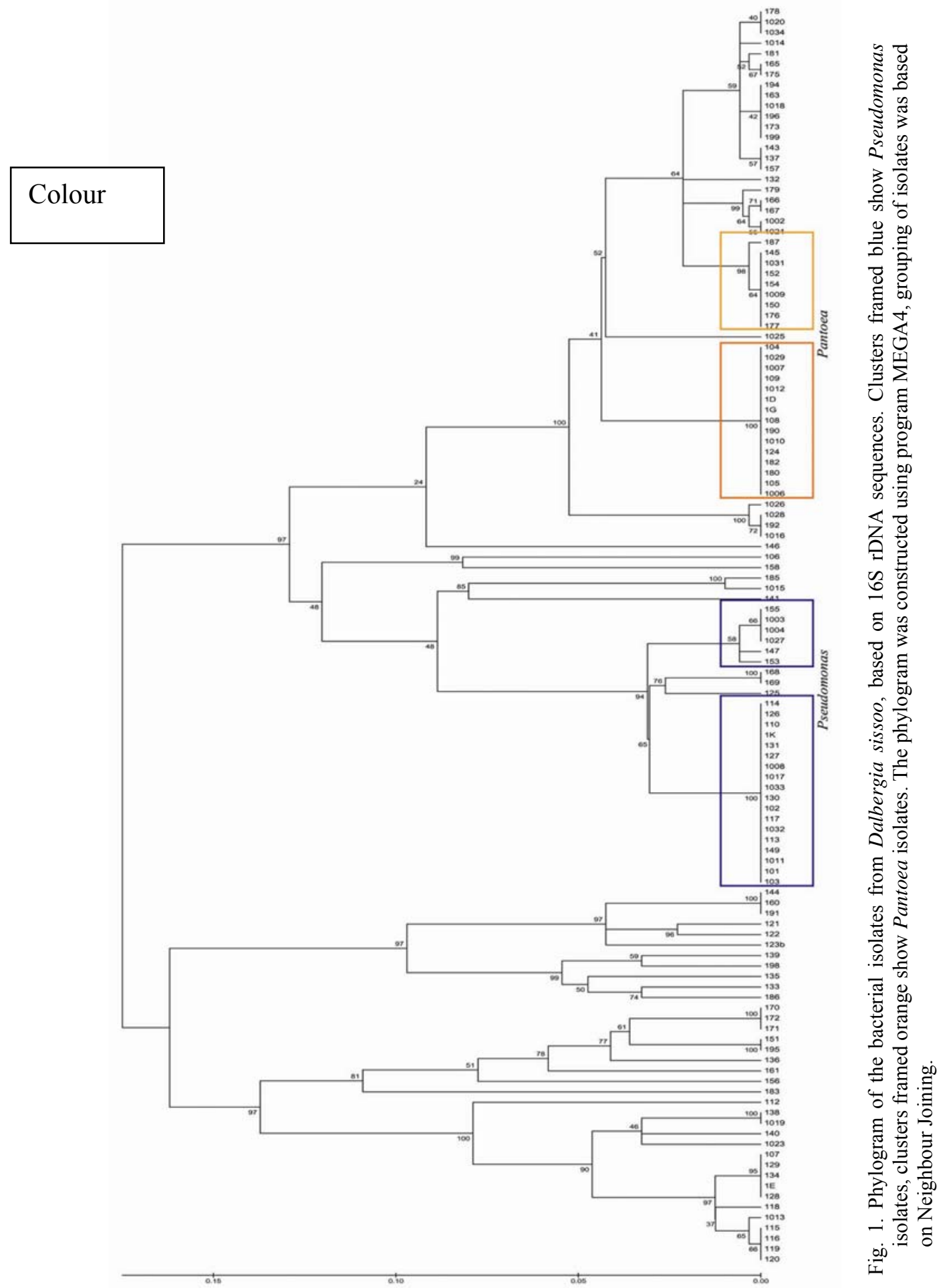


isolated in this study. The almost exclusive association of the well-known plant pathogenic genus Pseudomonas (Kennelly et al. 2007) with dieback affected sissoo trees prompted to investigate these isolates in more detail. Also, bacteria of this genus had been identified in earlier studies on sissoo dieback (Tantau et al. 2005). Biochemical analyzes showed that, as expected, all isolates identified as Pseudomonas by $16 \mathrm{~S}$ rDNA sequencing were Gram-negative and catalase positive. However, the isolates differed in their oxidase activity. Only the isolates 103, 126, 146, 147, 149, 153, 402, 403 and 1011 showed oxidase activity, while all other isolates did not (Fig. 2B).

In addition to $16 \mathrm{~S}$ rDNA sequences, 23 of the Pseudomonas isolates were further analyzed by AFLP. The analysis revealed three main clusters, clearly separated from each other by high bootstrap values (Fig. 2A, clusters I, II and III with the respective bootstrap values of 100, 97 and $85.8 \%$ each). From the reference strains of Pseudomonas used in this study, only Pseudomonas tremae grouped with a bootstrap value of $85.8 \%$ to cluster III, none of the others grouped within any of the clusters. Interestingly, all isolates found in clusters II and III are clustering together in a very homogeneous subcluster (bootstrap value 100\%) based on 16S rRNA sequences (Fig. 1), while the isolates of cluster I $(155,1003$ and 1004) are represented in the minor Pseudomonas subcluster (Fig. 1).

To limit the characterization of isolates to those potentially involved in the dieback disease of sissoo, their ability to evoke a hypersensitive response (HR) on indicator plants was tested. An isolate was considered pathogenic if it induced a positive HR in at least one of the three indicator plant species. Some Pseudomonas isolates provoked an untypical phenotype on the infiltrated leaves of S. lycopersicum, which appeared as red pigmentation all over the infiltrated leaf surface. With only two exceptions (isolates 147 and 1011) all the other tested 21 Pseudomonas isolates were able to induce a hypersensitive response in at least one of the indicator plants, confirming their plant pathogenic potential (Fig. 2B). There was an interesting coincidence between the ability to induce HR on indicator plants and the clusters built on AFLP basis (Fig. 2). Even the untypical reaction on tomato plants could be observed in all three isolates of cluster I as well as in the isolates $110,1 \mathrm{~K}, 1011$, which build a subcluster in cluster II. The enzyme activity of oxidase is also reflected in the clustering. For instance, isolates 149 and 103 share the same features and group together in a subcluster of cluster II by a bootstrap value of $100 \%$. Cluster I is very uniform with respect to the results of all investigations. The three isolates stem from trees at the nearby located sites Tangail and Jamuna Road, proved to be HR-positive in C. quinoa and N. t. 'Xanthi' showing an untypical HR in tomato plants and a lack of oxidase activity.

In contrast, cluster II harbors isolates from two regions (Tangail and Bogra), which behave differently in the HR assay and show different morphological characteristics. Except for the isolates $1 \mathrm{~K}, 110,113$ and 1011, all isolates in this cluster were clearly identified as HR-positive in all tested plants (including S. lycopersicum). OTUs in cluster II that were building subclusters showed the same biological and biochemical characteristics in most of the cases, for example the isolates 149 and 103 or 114 and 1008. Isolates 117 and 126, which together with the plant pathogenic reference strain $P$. tremae build cluster III, originate from two trees located at Tangail. These isolates were tested HR-positive in all plants, but differed in oxidase activity. All Pseudomonas isolates from roots $(402,414$ and 403), which were found in samples from a tree at Tangail with medium dieback-symptoms, are distantly related according to their individual position in the AFLP dendrogram. Although, all proved positive in HR assays and 402 and 403 showed oxidase activity (Fig. 2A and B). Among the isolates that are outside of these three main clusters no significant correspondence of their characteristics was found.

Bacteria can harm their hosts in various ways for example through the secretion of enzymes (Magro et al. 1994), polysaccharides (Denny 1995), phytohormones (Abramovich et al. 2006, Yang et al. 2007) or secondary metabolites. Among the secondary metabolites, the toxins are of 


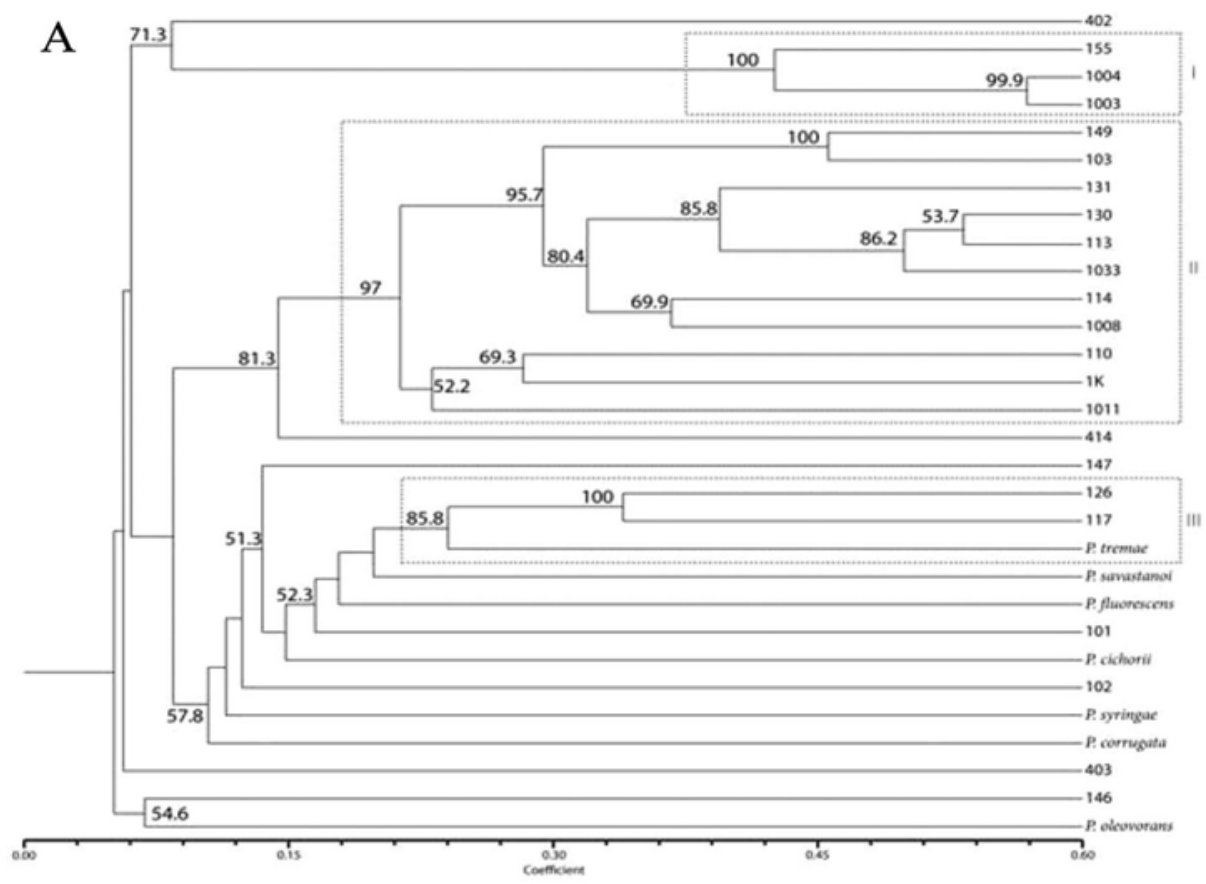

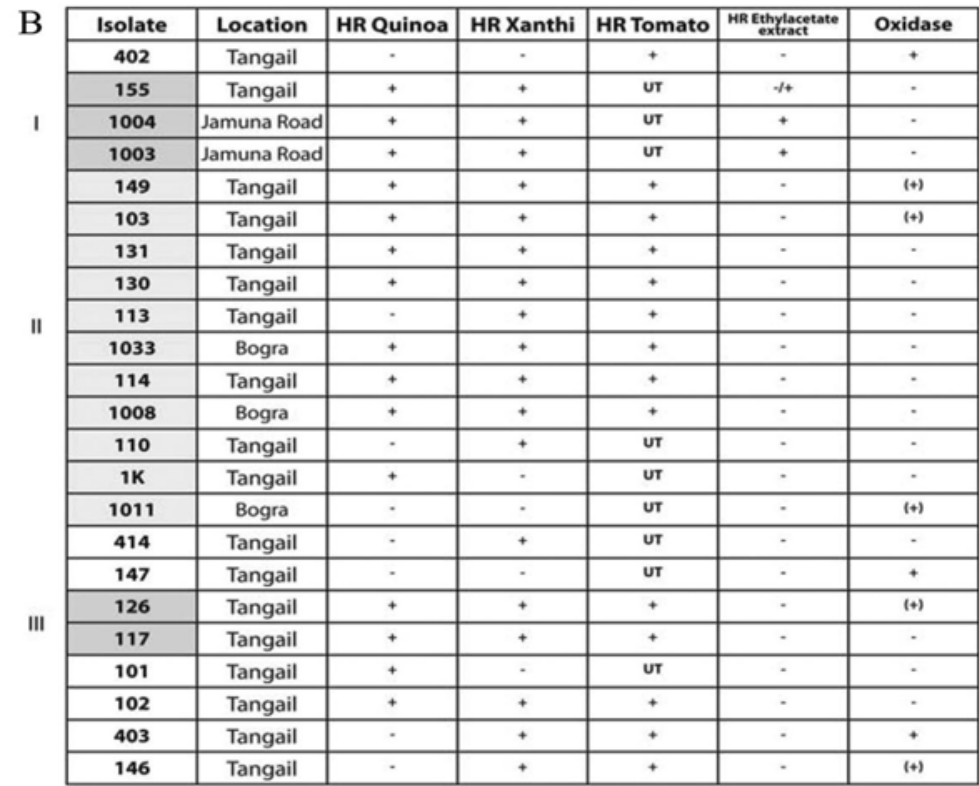

Fig. 2. A: Dendrogram of the AFLP analysis of Pseudomonas isolates. The dendrogram was calculated with Jaccard similarities and using UPGMA for clustering. All significant bootstrap values are specified on the respective node. The cophenetic correlation coefficient is $r=0.95661$. The clusters to be considered in this analysis are framed (I, II, III). B: Hypersensitive response assays (HR) and oxidase activity assays of the respective Pseudomonas isolates on indicator plants. HR Quinoa: Chenopodium quinoa; HR 'Xanthi': Nicotiana tabacum cv. 'Xanthi'; HR tomato: Solanum lycopersicum. HR ethylacetate extract: Extract tested on N. t. 'Xanthi'. +: positive reaction, $(+)$ : Retarded positive reaction, -: Negative reaction; UT: Untypical symptoms. 
great importance for plant pathology (Amusa 2006). In the case of Pseudomonas, there are several species producing toxins: $P$. syringae produces coronatine, tabtoxin and phaseolotoxin, $P$. corrugata produces corpeptin and P. marginalis produces viscosin (Bender et al. 1999, Kimura et al. 2001). In order to investigate whether the pathogenic potential of Pseudomonas isolates is based on toxic compounds, the effect of extracted secondary metabolites was tested. Among all tested isolates only the extracts of isolates 1003 and 1004 induced typical necrotic lesions on tobacco leaves. Interestingly, the secondary metabolite extract of isolate 155, which groups close to 1003 and 1004 both in 16S rRNA and AFLP analyses, also induced necrotic lesions in the HR assay, though less remarkable ones.

Among the broad spectrum of bacterial genera isolated from $D$. sissoo trees the dominant presence of members of the genus Pseudomonas is noticeable. This genus includes plant pathogenic as well as saprophytic members, which might be present as opportunistic agents instead of being the cause of the disease itself. Therefore, their ability to provoke disease symptoms in sissoo seedlings after mechanical administration of selected isolates was investigated.

\section{Colour}
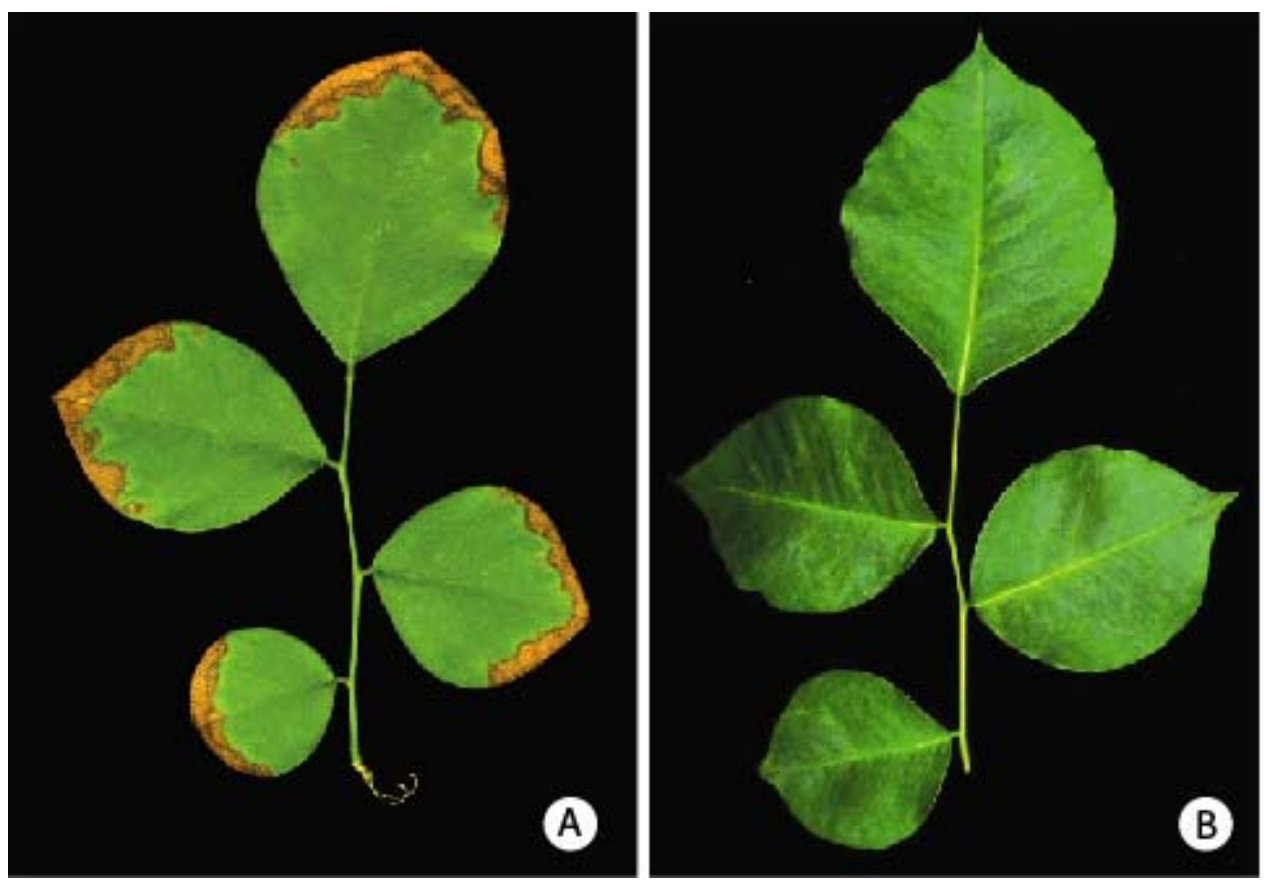

Fig. 3A-B. A. Typical disease symptoms (necroses) on the leaf of a Dalbergia sissoo seedling after infiltration with Pseudomonas bacteria isolated from a dieback affected sissoo tree in Bangladesh. B. Leaf from a sissoo seedling infiltrated with water.

Representative isolates of cluster I (1003 and 1004) and cluster II (113 and 1008) shown in Fig. 2 were used for inoculation experiments on sissoo seedlings. Isolates 1003 and 1004 were both sampled from the same tree at Jamuna Road and proved HR positive in C. quinoa and N. t. 'Xanthi'. Isolate 113 was sampled from a diseased tree at Tangail and was tested HR positive in all plants but C. quinoa. Isolate 1008 originated from a diseased tree at Bogra and was invariably HR positive among all indicator plants. 
When inoculated with the Pseudomonas isolates 113, 1003 and 1008, D. sissoo trees showed strong necrosis on the inoculated leaves, while inoculation with isolate 1004 caused fewer and weaker symptoms. The data were recorded over a period of $5-13$ months post inoculation. In general, necroses were predominantly found at the leaf margin (Fig. 3A) which is in contrast to necrotic spots observed on leaves of 12 - 15 years old dieback affected trees in Bangladesh. Those lesions were more frequently distributed on the lamina. Leaves of control plants, treated with water, did not show any necrotic alterations (Fig. 3B). The statistical analysis revealed a significant effect of the treatment with bacteria at all, (GLZ, $d f=3, p=0.036)$ but not of the mass of bacteria administered (GLZ, $\mathrm{df}=1, \mathrm{p}=0.998$, data not shown). With the exception of the isolate 1004 , the other three isolates caused symptoms in $D$. sissoo which significantly differed from the control treatment (Table 2).

Table 2. Statistical analysis of the symptom expression in Dalbergia sissoo plants after inoculation with bacteria isolated from dieback-affected sissoo trees.

\begin{tabular}{lccc}
\hline Treatment & $\begin{array}{c}\text { Symptom expression } \\
(\text { Mean } \pm \mathrm{SE})\end{array}$ & $\begin{array}{c}\text { Number of } \\
\text { replicates }\end{array}$ & P-value \\
\hline Control & $1.76 \pm 0.25$ & 4 & - \\
Isolate 113 & $3.75 \pm 0.15$ & 8 & 0.0232 \\
Isolate 1003 & $3.6 \pm 0.31$ & 10 & 0.0203 \\
Isolate 1004 & $2.5 \pm 0.19$ & 8 & 1 \\
Isolate 1008 & $4 \pm 0$ & 10 & 0.0025 \\
\hline
\end{tabular}

Data were analyzed using the Kruskal-Wallis-ANOVA and a corresponding post hoc analysis for non-parametric data. All isolates were tested against the control treatment.

Although infection experiments on trees are known to be very difficult to perform, a clear response of the natural host species after inoculation with three of the here isolated Pseudomonas strains was observed. The importance of the genus among tree diseases has been reported before (Cazorla et al. 1998, Menard et al. 2003, Scortichini et al. 2005, Green et al. 2010) and the efforts to understand the pathogenicity of Pseudomonas have provided new approaches for the detection and isolation of this pathogen. There is growing evidence for some Pseudomonas species to have the ability to modify host metabolism to their own advantage through effectors and toxins (Rico et al. 2011). Such metabolic modifications might explain some of the typical dieback symptoms of sissoo trees like necrosis and successive loss of the crown as a consequence of disturbed water transport. Furthermore, some Pseudomonas toxins and effectors are known to interfere with chloroplast functions, which results in nitrogen mobilization and suppression of plant defense, enabling the bacteria to proliferate inside the plant (Rico et al. 2011). In addition to toxins and effectors many Pseudomonas syringae strains produce plant hormones or plant hormone inducers (e.g. indole-3-acetic acid, $\gamma$-aminobutyric acid) manipulating and affecting the plant physiology (Cao et al. 2011). Interestingly, a recent scanning electron microscopic investigation of $D$. sissoo seedlings, which were experimentally infected with Pseudomonas isolate 1003, revealed cancerous proliferation of phloem tissue and stem necrosis (Tantau et al. 2011). The impact of the bacterial intervention in this way is still not well understood, though it is certainly an important key to the understanding of the infection process of many plant diseases.

Identifying bacteria from the genus Pseudomonas is a very difficult task even when using the most modern techniques available (Ait Tayeb et al. 2005). Identifying a specific bacterium as the potential cause of a disease is even more so. Nevertheless, in the present investigation not only the association of Pseudomonas with dieback-affected D. sissoo trees was confirmed, but also the pathogenic potential of Pseudomonas isolates could be demonstrated. 


\section{Acknowledgments}

The authors thank Drs. Sk. Shamimul Alam and Mihir Lal Saha, Department of Botany, University of Dhaka, Bangladesh, and Dr. M. Salim Khan, BCSIR Laboratories, Tissue Culture Section, Dhaka-1205, Bangladesh, for their help during sample collection and for stimulating discussions. The excellent technical assistance of Heidrun Meyer is gratefully acknowledged. Authors also thank Juan Enrique Valdez for image editing, Dr. Richard Splivallo for critically reading the manuscript and Thilo Eichenberg, StatSoft (Europe) GmbH, Hamburg, for statistical advice and software adaptation. This work was generously supported by Ilse Tantau and by the Friedrich Ebert Foundation through a Ph. D. scholarship to Nayuf Valdez.

\section{References}

Abramovitch RB, Anderson JC and Martin G 2006. Bacterial elicitation and evasion of plant innate immunity. Nat. Rev. Mol. Cell Biol. 7: 601-611.

Ait Tayeb L, Ageron E, Grimont F and Grimont PAD 2005. Molecular phylogeny of the genus Pseudomonas based on rpoB sequences and application for the identification of isolates. Res. Microbioloy 156: 763-773.

Amusa NA 2006. Microbially produced phytotoxins and plant disease management. African J. Biotech. 5(5): 405-414.

Bajwa R and Javaid A 2007. Integrated disease management to control Shisham (Dalbergia sissoo Roxb.) decline in Pakistan. Pak. J. Bot. 39(7): 2651-2656.

Baksha MW and Basak AC 2000. Mortality of sissoo (Dalbergia sissoo Roxb.) in Bangladesh. In: Appanah S, Allard G and Amayta SM (Eds.) Proceedings of International Seminar on Die-back of Sissoo, Nepal, 25-28 April, 2000. Field document-FORSPA 18: 1-4.

Baksha MW and Basak AC 2003. Mortality of sissoo (Dalbergia sissoo Roxb.) and its management in Bangladesh. In: Baksha MW (Ed.) Mortality of sissoo (Dalbergia sissoo) and top dying of Sundri (Heritiera fomes) in Bangladesh. Chittagong, Bangladesh Forest Research Institute: 1-6.

Bakshi BK 1954. Wilt of Shisham (Dalbergia sissoo Roxb.) due to Fusarium solani sensu Snyder and Hansen. Nature 174: 278.

Basak AC, Baksha MW and Khair MA 2003. Symptom and extent of damage caused by wilting of sissoo (Dalbergia sissoo Roxb.) in Bangladesh. In: Baksha MW (Ed.) Mortality of sissoo (Dalbergia sissoo) and top dying of Sundri (Heritiera fomes) in Bangladesh. Chittagong, Bangladesh Forest Research Institute pp. 39-42.

Bender CL, Alarcón-Chaidez F and Gross DC 1999. Pseudomonas syringae Phytotoxins: Mode of action, regulation, and biosynthesis by peptide and polyketide synthetases. Microbiol. Mol. Biol. Rev. 63 (2): 266-292.

Brady CL, T Goszczynska T, Venter SN, Cleenwerck I, De Vos P, Gitaitis RD and Coutinho TA 2011. Pantoea allii sp. nov., isolated from onion plants and seed. Int. J. Syst. Evol. Microbiol. 61(4): 932-937

Brown, MB and Forsythe AB 1974. Robust tests for the equality of variances. J. Am. Stat. Assoc. 69: 264-267.

Cao FY, Yoshioka K and Desveaux D 2011. The roles of ABA in plant-pathogen interactions. J. Plant Res. 124: 489-499.

Cazorla FM, Torés JA, Olalla L, Perez-García A, Farré JM and de Vicente A 1998. Bacterial apical necrosis of mango in Southern Spain: A disease caused by Pseudomonas syringae pv. syringae. Phytopathology 88(7): 610-620.

Coenye T and Vandamme P 2003. Diversity and significance of Burkholderia species occupying diverse ecological niches. Environ. Microbiol. 5(9): 719-729.

Collins M, An SI, Cai W, Ganachaud A, Guilyardi E, Jin FF, Fochum M, Legaigne M, Power S, Timmermann A, Vecchi G and Wittenberg A 2010. The impact of global warming on the tropical Pacific ocean and El Nino. Nat. Geosci. 3: 391-397. 
Dayaram, Kumar M, Shama S and Chaturvedi OP 2003. Shisham Mortality in Bihar: Extent and causes. Indian Phytopath. 56: 384-389.

Delétoile A, Decré D, Courant S, Passet V, Audo J, Grimont P, Arlet G and Brisse S 2009. Phylogeny and identification of Pantoea species and typing of Pantoea agglomerans strains by multilocus gene sequencing. J. Clinic. Microbiol. 47(2): 300-310.

Denny TP 1995. Involvement of bacterial polysaccharides in plant pathogenesis. Ann. Rev. Phytopathol. 33: 173-197.

Dunleavy JM 1989. Curtobacterium plantarum sp. nov. is ubiquitous in plant leaves and is seed transmitted in soybean and corn. Int. J. Syst. Bacteriol. 39(3): 240-249.

Escobar, MA and Dandekar AM 2003. Agrobacterium tumefaciens as an agent of disease. Trends in Plant Science 8(8): 380-386.

Green S, Studholme DJ, Laue BE, Dorati F, Lovell H, Arnold D, Cottrell JE, Bridgett S, Blaxter M, Huitema E, Thwaites R, Sharp PM, Jackson RW and Kamoun S 2010. Comparative genome analysis provides insights into the evolution and adaptation of Pseudomonas syringae pv. aesculi on Aesculus hippocastanum. PLoS One 5(4): e10224.

Guidot A, Elbaz M, Carrère S, Siri MI, Pianzzola MJ, Prior P and Boucher C 2009. Specific genes from the potato brown rot strains of Ralstonia solanacearum and their potential use for strain detection. Phytopathology 99(9): 1105-1110.

Jaccard P 1908. Nouvelles recherches sur la distribution florale. Bull. Soc. Vaud. Sci. Nat. 44: 223-270.

Kay S and Bonas U 2009. How Xanthomonas type III effectors manipulate the host plant. Curr. Opin. Microbiol. 12: 37-43.

Kennelly MM, Cazorla FM, de Vicente A, Ramos C and Sundin GW 2007. Pseudomonas syringae diseases of fruit trees - Progress toward understanding and control. Plant Dis. 91: 4-16.

Khan MM and Khan MH 2000. Die-back of Dalbergia sissoo in Pakistan. In: Appanah S, G Allard and SM Amayta (Eds.) Proceedings of International Seminar on Die-back of Sissoo, Nepal, 25-28 April, 2000. Field document-FORSPA, No.18. pp. 51-57.

Kimura M, Anzai H and Yamaguchi I 2001. Microbial toxins in plant-pathogen interactions: Biosynthesis, resistance mechanisms and significance. J. Gen. Appl. Microbiol. 47: 149-160

King EO, Ward MK and Raney DE 1954. Two simple media for the demonstration of pyocyanin and fluorescein. J. Lab. Clin. Med. 44: 301-307.

Lakso JU and Starr MP 1970. Comparative injuriousness to plants of Erwinia spp. and other enterobacteria from plants and animals. J. Appl. Bacteriol. 33: 692-707.

Magro P, Varvaro L, Chilosi G, Avanzo C and Balestra GM 1994. Pectolytic enzymes produced by Pseudomonas syringae pv. glycinea. FEMS Microbiology Letters 117: 1-5.

Menard M, Sutra L, Luisetti J, Prunier JP and Gardan L 2003. Pseudomonas syringae pv. avii (pv. nov.), the causal agent of bacterial canker of wild cherries (Prunus avium) in France. Eur. J. Plant Pathol. 109 (6): $565-576$

Nishijima KA, Couey HM and Alvarez AM 1987. Internal yellowing, a bacterial disease of papaya fruits caused by Enterobacter cloacae. Plant Dis. 71: 1029-1034.

Orwa C, Mutua A, Kindt R, Jamnadass R and Anthony S 2009. Agroforestree Database: A tree reference and selection guide version 4.0 (http://www.worldagroforestry.org/af/treedb/).

Reineke A and Karlovsky P 2000. Simplified AFLP protocol: Replacement of primer labeling by the incorporation of alpha-labeled nucleotides during PCR. BioTechniques 28: 622-623.

Rico A, McCraw SL and Preston GM 2011. The metabolic interface between Pseudomonas syringae and plant cells. Curr. Opin. Microbiol. 14: 31-38.

Rohlf FJ 2000. Numerical taxonomy and multivariate analysis system, Version 2.1. State University of New York, New York.

Sah SP, Sharma CK and Sehested F 2003. Possible role of the soil in the sissoo forest (Dalbergia sissoo Roxb.) decline in the Nepal terai. Plant Soil Environ. 49 (8): 378-385. 
Sambrook J, Fritsch EF and Maniatis T 1989. Molecular cloning: A laboratory manual, 2nd edition. Cold Spring Harbour Laboratory: Cold Spring Harbour, New York.

Schaad NW 1980. Laboratory Guide for the Identification of Plant Pathogenic Bacteria. The American Phytopathological Society, St. Paul, MN 3.

Scortichini M, Rossi MP, Loreti S, Bosco A, Fiori M, Jackson RW, Stead DE, Aspin A, Marchesi U, Zini $\mathrm{M}$ and Janse JD 2005. Pseudomonas syringae pv. coryli, the causal agent of bacterial twig dieback of Corylus avellana. Phytopathology 95(11): 1316-1324.

Sharma MK, Singal RM and Pokhriyal TC 2000. Dalbergia sissoo in India. Appanah S, G Allard and SM Amayta (Eds.) Proceedings of International Seminar Kathmandu, Nepal, 25-28 April 2000. Field document-FORSPA 18: 5-16.

Siegel S and Castellan NJ 1988. Nonparametric statistics for the behavioral sciences (2nd ed.) New York, McGraw-Hill.

Takahashi Y, Takahashi K, Sato M, Watanabe K and Kawano T 1997. Bacterial leaf rot of Odontioda orchids caused by Enterobacter cloacae. Ann. Phytopathol. Soc. Jpn. 63: 164-169.

Tantau H, Hoque MI, Sarker RH and Mühlbach HP 2005. 16S rDNA sequence analysis of bacterial isolates from die-back affected sissoo trees (Dalbergia sissoo Roxb.) in Bangladesh. J. Phytopathology 153: 517-521.

Tantau H, Renk S, Schultz D, Meyer H, Schulze J, Palm D, Stubbe A, Valdez Aguirre N, Sarker RH, Alam SkS, Saha M1, Khan MS, Hoque MI and Mühlbach HP 2011. Infectivity assays and sequence analyses for unassigned Pseudomonas species as putative cause of dieback disease of Dalbergia sissoo Roxb. in Bangladesh. Plant Tissue Cult. and Biotech. 21: 101-113.

Vogel S, Tantau H, Mielke-Ehret N, Hoque MI, Sarker RH, Saha ML, Alam SkS, Khan S and Mühlbach HP 2011. Detection of virus particles and double stranded RNA in dieback affected Dalbergia sissoo from Bangladesh. Bangladesh J. Bot. 40: 57-65.

Vos P, Hogers R, Bleeker M, Reijans M, van de Lee T, Hornes M, Fritjers A, Pot J, Peleman J, Kuiper M and Zabeau M 1995. AFLP: A new technique for DNA fingerprinting. Nucleic Acids Res. 23: 4407-4414.

White FF and Yang B 2009. Host and pathogen factors controlling the rice-Xanthomonas oryzae interaction. Plant Physiology 150: 1677-1686.

Wilson K 1997. Preparation of genomic DNA from bacteria. In: Ausubel FM, R Brent, RE Kingston, DD Moore, JG Seidman, JA Smith and K Struhl (Eds.). Current Protocols in Molecular Biology, New York City, NY: John Wiley and Sons Inc., pp. 2.4.1-2.4.5.

Yang S, Zhang Q, Guo J, Charkowski AO, Glick BR, Ibekwe AM, Cooksey DA and Yang CH 2007. Global effect of indole-3-acetic acid biosynthesis on multiple virulence factors of Erwinia chrysanthemi 3937. Appl. Environ. Microbiol. 73(4): 1079-1088.

Young JPW, Downer HL and Eardly BD1991. Phylogeny of the phototrophic Rhizobium strain BTAil by polymerase chain reaction-based sequencing of a $16 \mathrm{~S}$ rRNA gene segment. J. Bacteriol. 173: 2271-2277.

Zhang L and Birch RG 1997. The gene for albicidin detoxification from Pantoea dispersa encodes an esterase and attenuates pathogenicity of Xanthomonas albilineans to sugarcane. Proc. Natl. Acad. Sci. 94: 9984-9989.

(Manuscript received on 23 February, 2013; revised on 23 May, 2013) 